\title{
PENGARUH KUNYIT ASEM TERHADAP INTENSITAS \\ NYERI HAID PADA MAHASISWI SEMESTER 3 DI AKBID HARAPAN MULYA PONOROGO
}

\author{
Rindang Fitriana Ulfa ${ }^{1}$ Ambika Kurnia Mustikawati ${ }^{2}$ \\ ${ }^{12}$ Akbid Harapan Mulya Ponorogo \\ Email. Rindang.fitrianaulfa1992@gmail.com
}

\begin{abstract}
Menstrual pain is abdominal pain that comes from uterine cramps and occurs during menstruation. From the initial survey conducted by researchers, it was found that 10 menstruating students, 7 of whom experienced menstrual pain (70\%). One of the nonpharmacological treatments is giving tamarind turmeric. The purpose of this study was to determine whether there is an effect of tamarind turmeric on the intensity of menstrual pain in the 3rd Student of Harapan Mulya Ponorogo in 2020.

The research design used was a pre-experimental design, namely the one group pretest posttest design. The population studied were all students of the 3rd Semester of Akbid Harapan Mulya Year 2020 who experienced menstrual pain. Samples were obtained from a total of 16 people. Sampling was carried out by purposive sampling. Obtained from the observation sheet in the form of the NRS pain scale (Numeric Rating Scale Bournis), then the data were analyzed using the Wilcoxon test with $\alpha 0.05$.

The results of the research conducted showed that the menstrual pain felt by respondents before being given tamarind turmeric was mostly 9 respondents (56.2\%) experiencing mild menstrual pain and after being given Turmeric Asem to the 3rd Student of Harapan Mulya Academy in 2020 half of the respondents were 8 respodents (50\%) experienced mild menstrual pain. The results of the analysis show the value of $\rho=0.001$ ( $\rho$ $<\alpha)$ at a significant level of $95 \%$. It can be concluded that there is an effect of tamarind turmeric on the intensity of menstrual pain in 3rd students of Akbid Harapan Mulya Ponorogo. Based on the research results, it is expected that respondents can consume tamarind turmeric as an alternative treatment to treat menstrual pain because tamarind turmeric is a safe, inexpensive method, and without side effects
\end{abstract}

Key words : Menstrual Pain, tamarind turmeric

\begin{abstract}
Abstrak
Nyeri haid adalah nyeri perut yang berasal dari kram Rahim dan terjadi selama menstruasi. Dari survey awal yang dilakukan oleh peneliti didapatkan dari 10 mahasiwi yang menstruasi 7 diantaranya mengalami nyeri haid (70\%). Salah satu Pengobatan nonfarmakologi yaitu pemberian kunyit asem. Tujuan dari penelitian ini adalah mengetahui apakah ada pengaruh kunyit asem terhadap intensitas nyeri haid pada Mahasiswi Semester 3 Akbid Harapan Mulya Ponorogo Tahun 2020.

Desain penelitian yang digunakan adalah rancangan praeksperimen yakni rancangan one group pretest posttest. Populasi yang diteliti adalah semua Mahasiswi Semester 3 Akbid Harapan Mulya Tahun 2020 yang mengalami nyeri haid. Sampel diperoleh dari berjumlah 16 orang. Sampling dilakukan dengan cara purposive sampling Data diperoleh dari lembar observasi berupa skala nyeri NRS (Numeric Rating Scale Bournis), lalu dilakukan analisa data menggunakan uji Wilcoxon dengan $\alpha 0,05$.

Hasil penelitian yang di lakukan menunjukkan bahwa nyeri haid yang dirasakan responden sebelum diberikan Kunyit asem sebagian besar yaitu 9 responden (56,2 \%) mengalami nyeri haid ringan dan setelah diberikan Kunyit Asem pada Mahasiswi Semester 3 Akbid Harapan Mulya Tahun 2020 setengah dari responden yaitu 8 responden(50\%) mengalami nyeri haid ringan.
\end{abstract}


Hasil analisis menunjukkan nilai $\rho=0,001(\rho<\alpha)$ pada taraf signifikan $95 \%$. Dapat disimpulkan bahwa ada pengaruh kunyit asem terhadap intensitas nyeri haid pada mahasiswa Semester 3 Akbid Harapan Mulya Ponorogo. Berdasarkan hasil penelitian diharapkan responden dapat mengkonsumsi kunyit asem sebagai pengobatan alternatif untuk mengatasi nyeri haid karena kunyit asem merupakan metode yang aman, murah, dan tanpa efek samping.

\section{Kata kunci :Nyeri haid, Kunyit Asem}

\section{PENDAHULUAN}

Dismenorea merupakan nyeri perut pada bagian bawah yang terjadi pada saat menstruasi yang terkadang meluas hingga ke pinggang, punggung bagian bawah dan paha. Penyebab terjadinya dismenorea adalah adanya jumlah prostaglandin dari F2 $\alpha$ yang berlebihan pada darah menstruasi, sehingga merangsang hiperaktivitas uterus dan terjadinya kejang otot uterus. Berdasarkan penyebabnya dismenorea dibedakan menjadi dua, yaitu dismenorea primer dan sekunder. Dismenorea primer biasanya terjadi mulai dari pertama haid/menarche usia 10-15 tahun sampai usia 25 tahun yang disebabkan oleh konraksi uterus, dan tidak terdapat hubungan kelainan ginekologi. Sedangkan dismenorea sekunder disebabkan oleh kelainan yang terdapat dalam uterus dan saluran reproduksi. Angka kejadian nyeri menstruasi di dunia sangat besar. Rata-rata lebih dari 50\% perempuan di setiap negara mengalami nyeri mentruasi. Angka prosentasenya di Amerika sekitar $60 \%$ dan di Swedia sekitar 72\%. Sementara di Indonesia angkanya diperkirakan $55 \%$ perempuan usia produktif yang tersiksa oleh nyeri selama menstruasi. Angka kejadian (prevalensi) nyeri menstruasi berkisar 45 - 95\% di kalangan wanita usia produktif (Proverawati \& Misaroh, 2009).

Remaja putri akan lebih sering merasakan sakit akibat disemorea primer karena siklus hormonal yang belum begitu stabil. Hal hal yang dilakukan untuk mengurangi keluhan pada dismenorea primer, misalnya dengan penggunaan kompres hangat, mengkonsumsi obatobatan analgetik, olahraga teratur, akupuntur, dan mengkonsumsi produkproduk herbal/jamu yang telah dipercaya khasiatnya. Kebiasaan minum produk herbal/jamu salah satunya yaitu yang berbahan dasar kunyit salah satunya seperti kunyit asam, bukanlah hal yang asing bagi masyarakat Indonesia khususnya Jawa dan Madura. Jamu dapat dikategorikan sebagai minuman tradisional karena menggunakan bahanbahan alami seperti tumbuh-tumbuhan berkhasiat yang sudah biasa digunakan oleh masyarakat secara turun temurun.

Minuman kunyit adalah suatu minuman yang diolah dengan bahan utama kunyit. Secara alamiah memang kunyit dipercaya memiliki kandungan bahan aktif yang dapat Berfungsi sebagai analgetika, antipiretika, dan antiinflamasi. Selain itu dijelaskan bahwa Minuman kunyit sebagai pengurang rasa nyeri pada dismenore primer memiliki efek Samping minimal. Senyawa aktif atau bahan kimia yang terkandung dalam kunyit adalah kurkumin. Curcumine akan bekerja dalam menghambat rekasi cyclooxygenase(COX-2) sehingga menghambat atau mengurangi terjadinya inflamasi sehingga akan mengurangi atau bahkan menghambat kontraksi uterus.Dan curcumenol sebagai analgetik akan menghambat Pelepasan prostaglandin yang berlebihan melalui jaringan epitel uterus dan akan Menghambat kontraksi uterus sehingga akan mengurangi terjadinya dismenore.( Norton, 2008)

Berdasarkan studi pendahuluan yang diperoleh dari hasil wawancara pada 16 mahasiswi semester 3 AKBID Harapan Mulya Ponorogo menunjukkan bahwa 45 $\%$ mengatakan nyeri ringan, $40 \%$ nyeri sedang, $15 \%$ nyeri berat dan masih banyak mahasiswa yang belum mengetahui manfaat minuman kunyit sebagai pereda rasa nyeri saat menstruasi. Responden melakukan penanganan dismenorea dengan menggunakan minyak kayu putih, istirahat ditempat tidur, dan ada yang tidak melakukan apa-apa. Berdasarkan latar belakang tersebut maka peneliti tertarik melakukan penelitian pengaruh kunyit asem terhadap intensitas 
Nyeri haid pada mahasiswi semester 3 Di Akbid harapan mulya ponorogo

\section{METODE PENELITIAN}

Metode penelitian yang digunakan dalam penelitian ini adalah berdasarkan ada tidaknya perlakuan termasuk jenis rancangan penelitian Quasy eksperimental two group comparrison pre test post test design. Rancangan penelitian yang digunakan adalah One Group Pretest Postest. Dalam rancangan ini tidak ada kelompok pembanding (kontrol), tetapi sudah dilakukan observasi pertama (pretest) yang memungkinkan menguji perubahan perubahan yang terjadi setelah adanya eksperimen (program).

\section{HASIL PENELITIAN}

A. Distribusi Frekuensi intensitas nyeri haid sebelum konsumsi kunyit asam pada mahasiswi D3 kebidanan semester 3 Di Akbid harapan mulya ponorogo.

Tabel 1. Intesitas nyeri haid sebelum konsumsi kunyit asem

\begin{tabular}{lcc}
\hline Intensitas Nyeri & Frekuensi & $\begin{array}{c}\text { Presentase } \\
(\%)\end{array}$ \\
\hline Tidak Nyeri & 0 & 0 \\
Nyeri Ringan & 4 & 25 \\
Nyeri Sedang & 12 & 75 \\
Nyeri berat & 0 & 0 \\
Terkontrol & & 0 \\
Nyeri berat Tak & 0 & 100 \\
terkontrol & & \\
\hline Jumlah & 16 & 16 \\
\hline \multicolumn{2}{l}{ Sumber : Data Primer Penelitian Tahun } \\
2020
\end{tabular}

Berdasarkan tabel 1 dapat diinterprestasikan bahwa sebagian besar responden sebelum konsumsi kunyit asam memiliki intensitas nyeri sedang yaitu 12 responden $(75 \%)$.
B. Distribusi Frekuensi intensitas nyeri haid sesudah konsumsi kunyit asam pada mahasiswi Semester 3 Di Akbid Harapan Mulya Ponorogo

Tabel 2. Intesitas nyeri haid sesudah konsumsi kunyit asem

\begin{tabular}{lcc}
\hline Intensitas Nyeri & Frekuensi & $\begin{array}{c}\text { Presentase } \\
(\%)\end{array}$ \\
\hline Tidak Nyeri & 1 & $6 \%$ \\
Nyeri Ringan & 13 & $81 \%$ \\
Nyeri Sedang & 2 & $13 \%$ \\
$\begin{array}{l}\text { Nyeri berat } \\
\text { Terkontrol }\end{array}$ & 0 & $0 \%$ \\
$\begin{array}{l}\text { Nyeri berat Tak } \\
\text { terkontrol }\end{array}$ & 0 & $0 \%$ \\
\hline Jumlah & 16 & $100 \%$ \\
\hline
\end{tabular}

Sumber : Data Primer Penelitian Tahun 2020

Berdasarkan tabel 2 dapat diinterprestasikan bahwa hampir seluruh responden sesudah konsumsi kunyit asam pada remaja putri mengalami intensitas nyeri ringan sebanyak 13 responden $(81 \%)$ dan sebagian kecil responden tidak mengalami nyeri yaitu 1 responden $(6 \%)$.

C. Tabulasi Silang

Tabel 3 Tabulasi silang sebelum dan sesudah diberikan kunyit asem pada mahasiswi D3 kebidanan semester 3 Di Akbid harapan mulya ponorogo.

\begin{tabular}{|c|c|c|c|c|}
\hline \multirow{2}{*}{$\begin{array}{l}\text { Intensitas } \\
\text { Nyeri }\end{array}$} & \multicolumn{2}{|c|}{ Sebelum perlakuan } & \multicolumn{2}{|c|}{ Setelah perlakuan } \\
\hline & $\begin{array}{l}\text { frekue } \\
\text { nsi }\end{array}$ & Prosentase & $\begin{array}{l}\text { Frekuens } \\
\text { i }\end{array}$ & $\begin{array}{l}\text { Prosenta } \\
\text { se }\end{array}$ \\
\hline Tidak nyeri & 0 & $0 \%$ & 1 & $6 \%$ \\
\hline $\begin{array}{l}\text { Nyeri } \\
\text { Ringan }\end{array}$ & 4 & $25 \%$ & 13 & $81 \%$ \\
\hline $\begin{array}{l}\text { Nyeri } \\
\text { sedang }\end{array}$ & 12 & $75 \%$ & 2 & $13 \%$ \\
\hline $\begin{array}{l}\text { Nyeri berat } \\
\text { terkontrol }\end{array}$ & 0 & $0 \%$ & 0 & $0 \%$ \\
\hline $\begin{array}{l}\text { Nyeri berat } \\
\text { tak } \\
\text { terkontrol }\end{array}$ & 0 & $0 \%$ & 0 & $0 \%$ \\
\hline Jumlah & 16 & $100 \%$ & 16 & $100 \%$ \\
\hline $\begin{array}{l}\text { p- value }= \\
0,001\end{array}$ & & & & $\alpha=0,005$ \\
\hline
\end{tabular}


Berdasarkan tabel 3 dapat diinterpretasikan bahwa perbedaan intensitas nyeri haid sebelum dan sesudah konsumsi kunyit asam pada mahasiswa semester 3 Akbid Harapan Mulya Ponorogo hampir seluruh responden mengalami penurunun nyeri yaitu nyeri ringan sebanyak 13 responden $(81 \%)$ dan sebagian kecil responden tidak mengalami nyeri yaitu 1 responden (6\%).

Berdasarkan hasil uji statistik menggunakan uji statistik Wilcoxon Signed Ranks Test, diketahui bahwa hampir seluruh responden mengalami penurunan intensitas nyeri, hanya seorang responden intensitas nyerinya tetap. Besarnya nilai signifikan 0,001 dengan $\alpha$ 0,05 . Karena nilai signifikansi $<\alpha$ maka $\mathrm{H}_{0}$ ditolak dan $\mathrm{H}_{1}$ diterima yang berarti bahwa ada perbedaan intensitas nyeri haid pada mahasiswi semester 3 Akbid Harapan Mulya Ponorogo

\section{PEMBAHASAN}

Berdasarkan hasil penelitian yang dilakukan oleh peneliti tahun 2020 pada tabel 3 menunjukan dari 16 responden sebelum dan sesudah konsumsi kunyit asam terdapat perbedaan. Setelah mengkonsumsi kunyit asam responden mengalami penurunan intensitas nyeri haid. Sebagian besar responden $75 \%$ intensitas nyeri sedang dan $25 \%$ intensitas nyeri ringan sebelum mengkonsumsi kunyit asam berubah berkurang menjadi sebagian besar $81 \%$ intensitas nyeri ringan, $13 \%$ intensitas nyeri sedang dan $6 \%$ tidak nyeri. Hal ini menunjukkan bahwa setelah mengkonsumsi kunyit asam lebih baik jika dibandingkan dengan sebelum mengkonsumsi kunyit asam karena tingkat intensitas nyeri haid setelah mengkonsumsi kunyit asam lebih ringan (berkurang) bahkan menjadi tidak nyeri jika dibandingkan dengan tingkat intensitas nyeri haid sebelum mengkonsumsi kunyit asam.

Berdasarkan hasil ujian statistik menggunakan uji statistik Wilcoxon Signed Ranks Test diketahui bahwa hampir seluruh responden yaitu 15 orang $(81 \%)$ responden mengalami penurunan intensitas nyeri, hanya seorang responden intensitas nyerinya tetap pada intensitas ringan dan tidak ada satupun yang mengalami kenaikan intensitas nyeri. Didapatkan besarnya nilai signifikan $\rho$ value 0,001 adalah $<\alpha(0,05)$ yang menunjukkan perbedaan tersebut adalah signifikan, maka dari perbandingan kedua kejadian sebelum dan sesudah mengkonsumsi kunyit asam tersebut adalah ada perbedaan intensitas nyeri haid.

Salah satu manfaat dari curcumin, minyak atsiri, anthocyanin, dan tanin ada minuman kunyit asam berfungsi melakukan sistem blokade terhadap produksi prostaglandin dalam hal ini yaitu F2a (PGF2a) yang menyebabkan jumlah hormon prostalglandin menurun sehingga intensitas nyeri yang dirasakan pada remaja putri yang mengalami dysmenorrhea mulai berkurang. Selain itu juga sebagai relaksan otot yang mengalami kontraksi, dengan otot menjadi relaksasi, tekanan semakin bekurang sehingga secara otomatis dapat menurunkan nyeri yang dirasakan karena kondisi otot sudah tidak tegang (Marsaid, et.al. 2017).

Peneliti berpendapat bahwa kandungan curcumin dan minyak atsiri pada kunyit kombinasi anthocyanin dan tanin pada asam jawa dapat menurunkan tingkat nyeri menstruasi atau dysmenorrhea dengan memanfaatkan sistem blokade pembentukan zat biokimia tubuh yaitu prostalglandin yang merupakan reseptor stimulus nyeri tubuh sehingga tingkat nyeri pada dysmenorrhea dapat diminimalkan

Menurut penelitian yang dilakukan oleh maya safitri (2010) di STIKES Harapan Bangsa Purwokerto. Terdapat 20 mahasiswi program studi kebidanan STIKES Harapan Bangsa Purwokerto menunjukkan bahwa $45 \%$ mengatakan nyeri ringan, $40 \%$ nyeri sedang, $15 \%$ nyeri berat dan masih banyak mahasiswa yang belum mengetahui manfaat minuman kunyit sebagai pereda rasa nyeri saat menstruasi. Responden melakukan penanganan dismenorea dengan menggunakan minyak kayu putih, istirahat ditempat tidur, dan ada yang tidak melakukan apa-apa. 
Hal itu terjadi kemungkinan dari tidak adanya pendidikan kesehahatan mengenai pengobatan non farmakologi. Pengobatan farmakologi hanya didapatkan dari mata pelajaran farmakologi tidak membahas mengenai alternatif yang non

\section{DAFTAR PUSTAKA}

Aryani. (2010). Kesehatan Remaja Problem dan solusinya. Jakarta: Salemba Medika

Marsaid; Nurjayanti; Rimbaga, Yocykha, Ari. 2017. Efektifitas pemberian ekstrak kunyit asam terhadap penurunan dismenore pada remaja putri di desa tambang kecamatan pudak kabupaten ponorogo. Jurnal. Global Health Science. Vol. 2. Ponorogo

Maya Safitri. (2010) Pengaruh kunyit asam terhadap intensitas nyeri haid pada mahasiswa STIKES Harapan Bangsa: skripsi program studi ilmu kebidanan STIKES Harapan Bangsa

Norton K.J. (2008). Menstruation Disorder- cause, symptoms and Treatments of Dysmenorrhea.http://www.steadyheal th.com/articles/Menstruation_disorder _causes_symptoms_and_treatments_o faramakologi Dari data tersebut, maka pendidikan atau penyuluhan kesehatan di sekolah tersebut penting dilakukan, terutama masalah kesehatan reproduksi, dan sebagainya.

f_dysmenorrhea_a773.html. (Diakses tanggal 29 Januari 2015)

Notoatmodjo, S. (2010). Metode Penelitian Kesehatan. Jakarta: RinekaCipta.

Nursalam. (2011). Konsep dan Penerapan Metodologi Penelitian Ilmu Keperawatan. Jakarta: Salemba Medika.

Ozgoli, G., Goli, M. Moattar F. (2009). Comparison of effects of ginger, mefanamic acid, and ibuprofen on pain in women with primary dysmenorrhea. Retrieved januari, 2015:

http://books.google.co.id/books?id=7 WDgesSflScC\&printsec=frontcover\& $\mathrm{hl}=\mathrm{id \#} \mathrm{v}$-onepage $\& \mathrm{q} \& \mathrm{f}=$ true

Proverawati dan Misaroh. (2009). Menarche Mentruasi Pertama Penuh Makna. Yogyakarta: Nuha Medika

Purwanto dan Indarto. (2013). Kesehatan Berbasis Herbal. Yogyakarta: Gosyen Publishing 